\title{
Plexiform Neurofibromas in Neurofibromatosis Type 1- Two Families Case Report
}

\author{
Eltahir $\mathrm{Ali}^{1{ }^{12} *}$ and ILakkiapavai Devaraj ${ }^{\mathbf{1}}$ \\ ${ }^{1}$ Department of Human Genetics and Molecular Biology, Bharathiar University, India \\ ${ }^{2}$ Department of Molecular and Translational Medicine, University of Brescia, Italy
}

*Corresponding author: Eltahir Ali, A Nocivelli Institute for Molecular Medicine, Spedale Civilli di Brescia, Department of Molecular and Translational Medicine, University of Brescia, Brescia, Italy

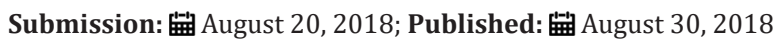

\begin{abstract}
Plexiform neurofibromas (PNFs) are distinct lesions in neurofibromatosis type 1 (NF1) patients and may arise anywhere along a nerve. PNFs occur in approximately $50 \%$ of individuals with NF1 and they have a capacity to transform into malignant peripheral nerve sheath tumors (MPNSTs) in $8 \%-13 \%$ of NF1 patients. In this study, we report four cases of NF1 with a PFN manifestation and the mutational analysis of the NF1 gene. The patients were from two families from Erode district, Tamil Nadu, South India. All the cases fulfilled the National Institutes of Health (NIH) diagnostic criteria of NF1, and had the major features of NF1 such as café-au-lait spots (CALS). cutaneous neurofibromas, plexiform neurofibromas and axillary freckling. Short stature is the minor NF1 feature that occurred in all the four cases. Mutations in the NF1 gene was detected by isolating the genomic DNA from each patient's blood sample and amplifying the NF1 gene using the polymerase chain reaction (PCR) technique. Two NF1 mutations c.5242C>T and c.2033_2034insC were detected in exon 13 and 29 respectively, by the Sanger sequencing method. Despite all the four patients had a PNF in a different part of the body, and those from the same family shared the same NF1 mutation, no genotype-phenotype correlations associated with the PNF have been identified.
\end{abstract}

Keywords: Plexiform neurofibroma; NF1 gene; Café-au-lait spots

Abbreviations: CALS: Café-au-laitSpots; MPNST: MalignantPeripheral Nerve Sheath Tumor; MRI: Magnetic Resonance Imaging; NF1: Neurofibromatosis Type 1; NIH: National Institutes of Health; PCR: Polymerase Chain Reaction; PNF: Plexiform Neurofibroma; YR: Year.

\section{Introduction}

Neurofibromatosis type 1 (NF1) is a common genetic disorder that affects 1 in 3000 individuals and is caused by deletion or point mutations of NF1, a tumor suppressor gene located on chromosome 17q11.2 [1]. The NF1 gene encodes neurofibromin; a cytoplasmic protein which controls cellular proliferation by inactivating the RAS -MAP kinase pathway [2]. NF1 is inherited as an autosomal dominant with complete penetrance and variable expression. Approximately $50 \%$ of the NF1 patients have no family history of the disorder [3]. The cardinal clinical features of NF1 include caféau-lait spots, axillary and inguinal freckling, iris Lisch nodules, neurofibromas, plexiform neurofibromas, and an increased risk of developing benign and malignant tumors, particularly optic glioma, neurofibrosarcoma, and malignant peripheral nerve sheath tumors (MPNSTs) [4].

Several studies have reported that approximately $5 \%-10 \%$ of all NF1 patients have a heterozygous deletion of usually $1.5 \mathrm{Mb}$ involving the NF1 gene and contiguous genes lying in its flanking regions which is caused by unequal homologous recombination of NF1 repeats [5-7]. NF1 patients with microdeletions show a more severe phenotype than the classical NF1 patients; this includes variable facial dysmorphisms, intellectual disability, developmental delay and an excessive number of neurofibromas for age $[8,9]$. Venturin and colleagues have reported that learning disability, cardiovascular malformation and dysmorphisms are the most extra-NF1 clinical signs in NF1 patients with microdeletions comparing with the whole NF1 population [1]. According to the National Institutes of Health (NIH) diagnostic criteria of NF1 [10], two or more of the following criteria are required for the diagnosis of NF1 in an individual:

A. Six or more café-au-lait macules $(>5 \mathrm{~mm}$ in children or $>15 \mathrm{~mm}$ in adults)

B. Two or more cutaneous or subcutaneous neurofibromas or one plexiform neurofibroma

C. Axillary or inguinal freckling

D. Two or more Lisch nodules (iris hamartomas) 
E. Optic pathway glioma

F. Bony dysplasia (sphenoid dysplasia, tibial dysplasia)

G. One first-degree relative with NF1

Some NF1 patients show mild symptoms while others show severe symptoms, but the mechanisms behind this clinical variations remain poorly understood and this may be because of the multiple factors involved in the pathogenesis of NF1 [11]. PNFs are diffuse benign tumors growing along the length of a nerve causing disfigurement. The function and growth of the affected site may also be compromised. They occur in approximately $50 \%$ of individuals with NF1, but most of PNFs are internal making their suspicion clinically difficult [12]. Some PNFs have a tendency to transform into malignant peripheral nerve sheath tumors (MPNSTs) and this was estimated to be in $8 \%-13 \%$ of NF1 patients $[13,14]$. The primary aim of this study was to identify the NF1 gene defect associated with the clinical presentation of four cases of NF1 with PNFs. The four cases were from two families in Erode district, South India. This study has been approved by the Institutional Ethics Committee, Bharathiar University, India. The ethical clearance number was IECBU04-397 and informed consent forms have been obtained from all the participated patients.

\section{Case Presentation}

\section{Case I}

An 18-year-old, unmarried male suffered from NF1. His paternal grandmother, two aunts (45yr and 40yr (case II)), father (58yr) and younger brother ( 9 months) were affected with NF1, but his other younger brother (5yr) was not affected. This patient had a very low number of neurofibromas but a very huge plexiform neurofibroma in the left thigh restraining his ability to walk properly (Figure 1). The magnetic resonance imaging (MRI) (MRI image is not provided with this report) revealed an ill-defined lobulated heterogeneous T2 hyperintense mass in the sacral central spinal canal. The lesion was seen extending along the lumbosacral plexus into the pelvis on the left side. The mass was seen displacing the rectum to the right. It was seen extending as a plexiform neurofibroma into the thigh and the leg. Involvement of the sciatic tibial, peroneal and the sural nerves were seen diffusely. Infiltration of the gluteal, vastus intermedius and lateralis muscles was noted. The femur, tibia and the fibula appeared normal with no erosion, marrow signal alteration. The patient had more than ten café-au-lait spots, scoliosis, short stature less than a $3^{\text {rd }}$ percentile, developmental delay, pectus carinatum, and learning disabilities. NF1 mutational analysis revealed that this patient had a nonsense mutation c.5242C > in exon 29.

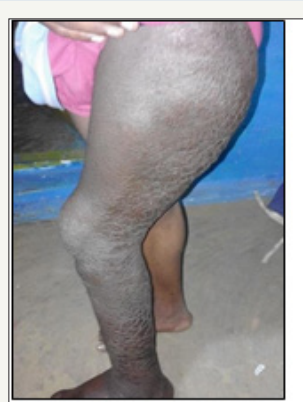

(A)

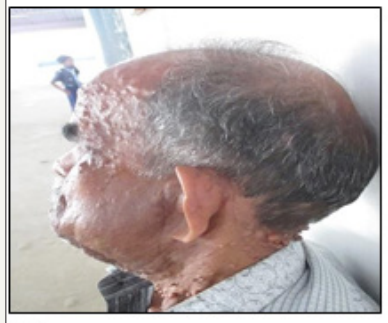

(C)

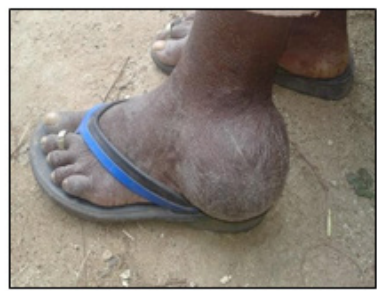

(B)

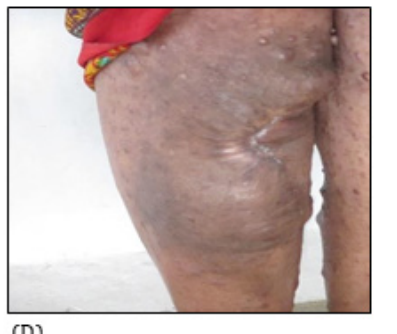

(D)

Figure 1: A plexiform neurofibroma in case I(A), case II(B), case III(C), and case IV(D).

\section{Case II}

A 40-year-old woman with familial NF1 of maternal origin, and her elder brother (58yr), sister (45yr), and nephew (case I) were also affected. She had a late onset of the cardinal features of NF1 (at age 34yr) except the café-au-lait spots. She had multiple caféau-lait spots, small size numerous cutaneous and subcutaneous neurofibromas, axillary freckling, facial dysmorphic features, short stature less than a 3 rd percentile, and frequent headache. No intellectual disability or behavioral changes was observed. She had a PNF in her left foot at the ankle region (Figure 1), but it did not restrain her ability to walk. The presence of iris Lisch nodules and optic glioma was not examined but the patient had no any vision problem. Her NF1 gene had the same mutation c.5242C > T in exon 29 as her nephew (case I).

\section{Case III}

A 64-year-old unmarried male with NF1. The age of onset of the neurofibromas was unknown but the defective NF1 gene was inherited from his mother who was affected with sporadic NF1. The patient had a younger sister (case IV) who was also affected with NF1 and four elder unaffected brothers. He had a 
facial plexiform neurofibroma on the left side displacing the left mandible and causing hearing loss in the right ear and low hearing ability in the left ear (Figure 1). The patient had a short stature less than a $3^{\text {rd }}$ percentile, multiple café-au-lait spots, too numerous to count cutaneous and subcutaneous neurofibromas, axillary freckling, macrocephaly, headache, large hands and feet, and facial dysmorphic features such as prominent forehead, large and low-set ears, broad nasal bridge and deep-set eyes. The Sanger sequencing of NF1 gene showed a frameshift mutation c.2033_2034insC in exon 13 .

\section{Case IV}

A 62-year-old unmarried woman with familial NF1. Her deceased mother and elder brother (case III) had NF1. The clinical examination revealed cutaneous and subcutaneous neurofibromas of variable shapes and sizes including eyelid neurofibromas, multiple café-au-lait spots, short stature less than a 3 rd percentile, macrocephaly, and axillary freckling. She also suffered from frequent headache, hearing impairment, and back pain. The early onset of neurofibromas and a plexiform neurofibroma at age $11 \mathrm{yr}$ may explain the too numerous to count lesions. The plexiform neurofibroma was in the anterior portion of her right leg, $>20 \mathrm{~cm}$ in length and $10 \mathrm{~cm}$ in width and most of the tumor was surgically excised (Figure 1) when she was 18yr due to a severe injury in that region. Like her brother (case III), this patient had the same NF1 mutation c.2033_2034insC in exon13.

\section{Discussion}

Neurofibromatosis type 1 (NF1) is a multisystem genetic disorder with an autosomal dominant inheritance, 100\% penetrance, and variable expression. Point mutations in NF1 gene or microdeletions of entire NF1 gene are the causes of NF1 [1]. The hallmark signs of NF1 include CALS, dermal neurofibromas, PNFs, Lisch nodules of the iris, optic nerve gliomas, scoliosis, and bony dysplasia. The primary objective of this study was to provide an exhaustive description of four cases of NF1 with a plexiform neurofibroma manifestation along with an analysis of NF1 mutation in each patient. All the patients in the present report fulfilled the National Institutes of Health Consensus Criteria for the diagnosis of NF1, and had familial mutations. PNFs have been reported to be in approximately half of all NF1 patients, and they have a potential to transform into MPNSTs in up to $13 \%$ of NF1 patients in their lifetime $[13,14]$. The size and location of the PNF was varied in the four NF1 patients with significant variation in severity. The most severe PNF was observed in case I and case III. Bone dysplasia is another common orthopedic manifestation of NF1 with a prevalence of $14 \%$ in NF1 population and usually manifesting within the first year of life [14]. The tibia is the most commonly affected bone bowing in an anterolateral direction. In the present report, two cases had bone dysplasia other than tibial dysplasia. Case I had scoliosis and pectus carinatum while case III showed left mandible dysplasia due to facial PNF on the left side. The analysis of NF1 mutations in the four NF1 patients has identified two different mutations in exons 13 and 29 , and these mutations were identified in previous studies $[15,16]$. Case I and his aunt (case II) shared the same nonsense mutation
c.5242C> T in exon 29 [15], while case III and his sister (case IV) had a frameshift mutation c.2033_2034insC in exon 13 [16].

NF1 shows considerable inter- and intra-familial variability in phenotypic expression. The existence of the same mutation in NF1 patients from the same family, and the variation in the severity of their conditions, suggest the difficulty in identification of clear-cut genotype-phenotype correlations. Till the date, only two genotypephenotype correlations have been identified. The first one is the association of NF1 microdeletion with more severe phenotypes than NF1 patients with point mutations $[8,9]$. The second genotypephenotype correlation is that NF1 patients who have a 3-bp inframe deletion (c.2970_2972 delAAT) in exon 17 do not develop cutaneous neurofibromas [17].

\section{Conclusion}

In this study, we report the clinical presentation of four NF1 cases with PNFs from two unrelated families, and the causative genetic defects. There was a variation in the size, position, and severity of the PNF among the patients. The severity of PNF ranges from mild in cases II and IV to very severe in cases I and III. However, in the cases II and IV, the PNF showed a mild manifestation, it caused inconvenience to the patients. Currently, there is no cure for the NF1, and early surgical removal of PNFs is recommended to avoid organ malfunction as seen in the cases I and III. The NF1 mutations detected in the this study were consistent with previously identified NF1 mutations. Despite the extensive research on the PNFs in NF1 patients there was no a genotype-phenotype correlation identified till the date. Further research on development of methods for early detection of PNFs is recommended because the growth of PNF internally in some patients makes the early detection of this neoplasm a daunting task.

\section{Acknowledgement}

The authors wish to thank all the patients for their participation in this study. We are very grateful to Dr. V. Balachandar for his support and to A. Devaraj, and Reem Rabih for their help in samples collection.

\section{Conflict of Interest}

The authors declare no conflict of interest.

\section{References}

1. Venturin M, Guarnieri P, Natacci F, Stabile M, Tenconi R, et al. (2004) Mental retardation and cardiovascular malformations in NF1 microdeleted patients point to candidate genes in $17 q 11$. 2. Journal of medical genetics 41(1): 35-41.

2. Tidyman WE, Rauen KA (2008) Noonan, Costello and cardio-faciocutaneous syndromes: dysregulation of the Ras-MAPK pathway. Expert Rev Mol Med 10: e37.

3. Ferner RE, Huson SM, Thomas N, Moss C, Willshaw H, et al. (2007) Guidelines for the diagnosis and management of individuals with neurofibromatosis 1. J Med Genet 44(2): 81-88.

4. De Raedt T, Brems H, Wolkenstein P, Vidaud D, Pilotti S, et al. (2003) Elevated risk for MPNST in NF1 microdeletion patients. Am J Hum Genet 72(5): 1288-1292. 
5. Dorschner MO, Sybert VP, Weaver M, Pletcher PA, Stephens K (2000) NF1 microdeletion breakpoints are clustered at flanking repetitive sequences. Hum Mol Genet 9(1): 35-46.

6. Jenne DE, Tinschert S, Reimann H, Lasinger W, Thiel G, et al. (2001) Molecular characterization and gene content of breakpoint boundaries in patients with neurofibromatosis type 1 with 17q11.2 microdeletions. Am J Hum Genet 69(3): 516-527.

7. Kluwe L, Siebert R, Gesk S, Friedrich RE, Sigrid Tinschert S, et al. (2004) Screening 500 unselected neurofibromatosis 1 patients for deletions of the NF1 gene. Hum Mutat 23(2): 111-116.

8. Upadhyaya M, Ruggieri M, Maynard J, Osborn M, Hartog C, et al. (1998) Gross deletions of the neurofibromatosis type 1 (NF1) gene are predominantly of maternal origin and commonly associated with a learning disability, dysmorphic features and developmental delay. Hum Genet 102(5): 591-597.

9. Wu B, Austin MA, Schneider GH, Boles RG, Korf BR (1995) Deletion of the entire NF1 gene detected by FISH: four deletion patients associated with severe manifestations. Am J Med Genet 59(4): 528-535.

10. National Institutes of Health (1988) National Institutes of Health Consensus Development Conference Statement: neurofibromatosis. Bethesda, Md., USA, July 13-15, 1987. Neurofibromatosis 1(3): 172-178.

11. Sabbagh A, Pasmant E, Laurendeau I, Parfait B, Barbarot S, et al. (2009) Unraveling the genetic basis of variable clinical expression in neurofibromatosis 1. Hum Mol Genet 18(15): 2768 -2778.
12. Mautner VF, Asuagbor FA, Dombi E, Fünsterer C, Kluwe L, at al. (2008) Assessment of benign tumor burden by whole-body MRI in patients with neurofibromatosis 1. Neuro Oncol 10(4): 593-598.

13. Evans DG, Baser ME, McGaughran J, Sharif S, Howard E, et al. (2002) Malignant peripheral nerve sheath tumors in neurofibromatosis 1. J Med Genet 39(5): 311-314.

14. De Bella K, Szudek J, Friedman JM (2000) Use of the national institutes of health criteria for diagnosis of neurofibromatosis 1 in children. Pediatrics 105(3 Pt 1): 608-614.

15. Kluwe L, Tatagiba M, Fünsterer C, Mautner VF (2003) NF1 mutations and clinical spectrum in patients with spinal neurofibromas. J Med Genet 40(5): 368-371.

16. Valero MC, Martín Y, Hernández Imaz E, Marina Hernández A, Meleán G, et al. (2011) a highly sensitive genetic protocol to detect NF1 mutations. J Mol Diagn 13(2): 113-122.

17. Upadhyaya M, Huson SM, Davies M, Thomas N, Chuzhanova N, et al (2007) An absence of cutaneous neurofibromas associated with a 3-bp inframe deletion in exon 17 of the NF1 gene (c.2970-2972 delAAT): evidence of a clinically significant NF1 genotype-phenotype correlation. Am J Hum Genet 80(1): 140-151.
Creative Commons Attribution 4.0 International License

For possible submissions Click Here

\section{Submit Article}

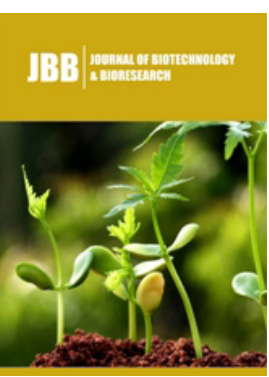

Journal of Biotechnology \& Bioresearch

\section{Benefits of Publishing with us}

- High-level peer review and editorial services

- Freely accessible online immediately upon publication

- Authors retain the copyright to their work

- Licensing it under a Creative Commons license

- Visibility through different online platforms 